\title{
Experiences of Family Members in Caring of Stroke Patients: A Case Study in the Border Provinces of the Upper Northeast of Thailand
}

\author{
Arunrat Utaisang ${ }^{1 *}$, Chatkane Pearkao ${ }^{2}$, Khunphitha Junsevg ${ }^{1}$, Amornrat Sangsaikaew ${ }^{1}$, Duangjai Boonkong ${ }^{1}$, \\ Chureerat Korcharoenyos ${ }^{1}$
}

${ }^{1}$ Department of Adult and Aging Nursing, Boromarajonani College of Nursing Nakhon Phanom, Nakhon Phanom University, Nai Mueang, Thailand; ${ }^{2}$ Department of Adult Nursing, Faculty of Nursing, Khon Kaen University, Khon Kaen, Thailand

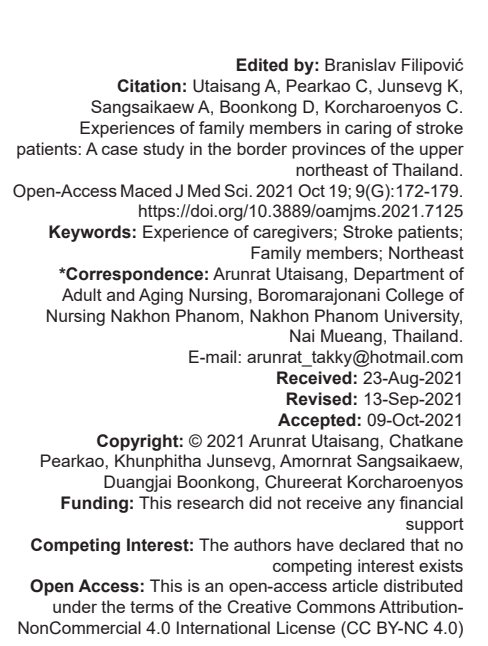

\section{Abstract}

BACKGROUND: Stroke patients require continued care, which makes stroke family caregivers unlikely to anticipate the end of home health-care service.

AIM: The objectives of this study aimed, therefore, to seek understanding of stroke family caregivers in relation to caring experience, problems and barriers, and needs of family caregivers in the context of border provinces of the upper northeast of Thailand.

METHODS: The current study was based on the phenomenological approach. The study samples included 16 informants. Data collection, conducted between February and August 2020, was performed using in-depth interviews. The collected data then were analyzed using the van Manen's approach.

RESULTS: Experiences of the stroke family caregivers were reflected and fell in van Manen's 4 points under 12 thematic categories: (1) Lived body including lack of knowledge, fatigue, and sense of obligation; (2) lived time including paying gratitude, uncertainty, and paying retribution; (3) lived space including just long distance, being isolated in the wide world and living in a remote area; and (4) lived relation including blood thicker than water community network, and needs from health-care services.

CONCLUSION: The findings may be exploited to develop health service preparedness for health outcome promotion for stroke patients and stroke family caregivers.

\section{Introduction}

Stroke is one of the critical health problems worldwide. According to the World Stroke Organization, stroke accounts for the 80 million deaths and 50 million disables worldwide. In the United States, stroke was responsible for 6.6 million [1], [2]. Meanwhile, in Thailand from 2016 to 2018, 399.88, 423.27, and 471.71 stroke patients were reported in 100,000 populations, respectively, and stroke is associated with one of the three causes of death. As for stroke patients, stroke survivors are reported to suffer from disability whose severity varies according to the position and type of stroke [3]. Indeed, stroke affects not only patient themselves but also caregivers, particularly their family members. To illustrate, stroke patients suffer from physical, emotional, and social effects; additionally, disability affecting functional mobility and stability makes them difficulty to perform activities of daily living as well as effects their image [3], [4]. Stroke, an incurable chronic disease, usually leaves the survivors prone to depend on caregivers for the rest of life [4]. A family with a stroke patient could suffer from all aspects of consequences such as physical, emotional, and social problems, concern about prognosis, unanticipated change, and death [5]. Particularly, a family member assigned to be the primary caregiver is subjected to his/ her role, which also affects their income [6], [7]. Caring for disable or paralyzed stroke patients requires the relevant specialized knowledge, skills, patience, love, and understanding, which may cause caregivers stress, anxiety, fatigue, or other health problems [8]. In the worst case that currently after hospital discharge, most post-stroke patients receive care from family members. However, stroke patients receiving care at home are prone to complications such as bedsores, respiratory infections, urinary infections, and join stiffness; thus, effective prevention of complication can reduce not only patient pain or suffering, alleviate family expenses but also minimize country's expenditures [9] Indeed, whether such complications can be mitigated depend on family members potential to provide effective care. Several quantitative studies suggest positive outcomes 
of stroke patients; however, health consequences of family caregivers in respect of physical, emotional, and social problems remain problematic [5]. In addition, to our knowledge, there are few qualitative studies investigating these problem, which may differ according to contexts.

The objectives of this study aimed, therefore, to seek understanding of stroke family caregivers in relation to caring experience, problems and barriers, and needs of family caregivers in the context of border provinces of the upper northeast of Thailand. The obtained findings may be used to develop health service preparedness designed to improve both stroke patients and caregivers' health outcomes.

\section{Methods}

In the current research, we used Consolidated criteria for Reporting Qualitative research [10], comprising three domains: Research team and reflexivity, study design, and analysis and findings. This qualitative research was based on hermeneutic phenomenology of Heidegger [11] who holds the belief that world and humans cannot be differentiated. Realistic experience was subject to interpretation using Van Manen four worlds [12]. It was to explore trustworthiness of what stroke family caregivers offered meaning of caring for stroke patients. The context study lied in border provinces upper northeastern. The researchers attempted to understand experiences perceived by caregivers of stroke patients and explore meaning for virtue understanding.

\section{Population and samples}

The population of study was family members who played the role as the primary caregiver for a stroke patient. They were selected by a purposive sampling. The specified characteristics of subjects included (1) being 18 years of age or over, (2) their care recipient having diagnosed with stroke and evaluated with ADL from 0 to 8 (severe dependence to absolute dependence), and (3) willing to offer information. Caregivers who met the inclusion criteria were presented a written consent form and informed that the participation was voluntary and that their refusal did not affect further treatment. The researchers ceased to collect data when data diversification of caregiving experiences for stroke patients reached data saturation.

\section{Research tool}

This study was conducted by researchers who were trained and experienced with the qualitative research methodology. Data were collected by (1) personal data record form of both the primary caregiver and care recipient dyad and (2) in-depth interview question (semi-structured interview). The following are examples of initial questions used in the study: Can you tell me the illness of the stroke patient under your care? How do you become the caregiver for this case? How do you feel when you provide care to this case? What are your routine duties you perform to provide care for this case? So far you have taken care of this case, what problem you have faced and how you have coped with them? Since the beginning of your care, what change of symptoms or signs you have noticed? and as a caregiver, what help do you need and from whom you need? In the event that the informant offered unclear answers, the researchers would ask probing questions as following examples: Can you elaborate your points? (3) Field note, which was taken once the researchers observed informants facial, emotional, and vocal expressions so as to reflect their feelings and emotions. The research tools were validated for content validity from three experts: One was a nursing teacher expert in qualitative research approach and the others were nurses working in a stroke nursing care unit.

\section{Subject's rights protection}

This research was approved by human research ethic committee (Code: NP-EC11 NO2/22563). Data collection took place from February 2020 to February 2021. After the project approval, the researchers approached the research subjects for selfintroduction and creating interpersonal relationship. The subjects were informed of research objectives, procedures of data collection, and research implication. They were acknowledged that research participation did not affect any further treatment; that the information obtained from this research was kept confidential; that neither name nor surname of the subjects was disclosed in the research report. The subjects were also informed of overall research interest and research contribution. All data were stored in the computer to which no one was allowed to reach database. One year after research completion, all data were subjected to delete. To do voice recording, it must be allowed by the subjects. After receiving explanation and instruction, if willing to participate in the research, the subjects singed a consent form. The subjects were declared that they can cease the participation anytime without effects to their benefits in health service systems.

\section{Data collection and data analysis}

As for data collection, researchers contacted the health personnel working at a stroke ward to approach informants. In-depth interview lasted 60-90 min. The informants were subjected to interview twice. The interview 
took place at a conference room, outpatient building, Nakhon Phanom Hospital, or at the caregiver' location and availability in which privacy and noise disturbance were free. The data were collected from February to August 2020. There were a total of 16 informants, which reached data saturation. During the interview reactions, feelings and emotions of the informants were observed and underwent note taking. Second appointment was made in the event that some unclear information emerged during record transcription. Out of 16 , two informants offered unclear information and were contacted for addition interview. The general information of the informants including age, sex, education, career, and duration of care providing were also collected for discussion of results and qualitative data analysis.

The collected data were analyzed using van Manen [11] thematic analysis comprising six research activities: (1) Understanding lived experience step by step so as to set research questions and design interview questions for profound information; (2) investigating lived experience as if we were in their settings; meanwhile, carefully considering the obtained data in parallel with field note; (3) identifying and elucidating essential themes by categorizing group meaning previously defined so as to find relationship. The relationship obtained was subjected to discussion among research team members and the experts using analysis and interpretive framework of van Manen's [11] four lived world; (4) describing phenomenal experience and selecting excepts and examples to support meaning presented; (5) finding relevancy of phenology studied wherein research team and informants jointly examined; and (6) balancing principal and secondary themes to reflect lived experiences for research reliability.

\section{Data reliability}

Trustworthiness was validated using the criteria of Lincoln and Guba [13], including selecting the informants with direct experience providing care for stroke patients under phenomenological study (credibility), presenting interpretation of meaning with sufficient and detailed information so as to be generalized to similar contexts (transferability), supervising research procedures by the research team who can make decisions and agree with the findings without conflicts (dependability), and writing or recording activities and viewpoints the research team could verify (dependability).

\section{Results}

Table 1 shows there were a total of 16 informants, 13 of whom were female and three males, with an age ranging from 21 to 68 years. There were 10 Thai, four
Table 1: Characteristics of respondents $(n=16)$

\begin{tabular}{|c|c|c|}
\hline Demographic characteristics & $\mathrm{n}$ & $\%$ \\
\hline \multicolumn{3}{|l|}{ Sex } \\
\hline Females & 3 & 18.75 \\
\hline Males & 13 & 81.25 \\
\hline \multicolumn{3}{|l|}{ Age (years) } \\
\hline 18-35 & 2 & 12.50 \\
\hline $36-59$ & 10 & 62.50 \\
\hline$\geq 60$ & 3 & 18.75 \\
\hline \multicolumn{3}{|l|}{ Race } \\
\hline Thai & 10 & 62.50 \\
\hline Laos & 4 & 25.00 \\
\hline Vietnamese & 2 & 12.50 \\
\hline \multicolumn{3}{|l|}{ Religion } \\
\hline Buddhist & 13 & 81.25 \\
\hline Christian & 3 & 18.75 \\
\hline \multicolumn{3}{|l|}{ Marital status } \\
\hline Married & 11 & 68.75 \\
\hline Single & 5 & 31.25 \\
\hline \multicolumn{3}{|l|}{ Education attainment } \\
\hline Compulsory education & 8 & 50.00 \\
\hline High school & 2 & 12.50 \\
\hline Vocational/high vocational certificate & 2 & 12.50 \\
\hline Undergraduate degree & 1 & 6.25 \\
\hline Bachelor's degree & 2 & 12.50 \\
\hline Illiterate & 1 & 6.25 \\
\hline \multicolumn{3}{|l|}{ Relationship to patients } \\
\hline Wife & 5 & 31.25 \\
\hline Husband & 3 & 18.75 \\
\hline Children & 6 & 37.50 \\
\hline Grandchildren & 2 & 12.50 \\
\hline \multicolumn{3}{|l|}{ Regarding career } \\
\hline Employment & 2 & 12.50 \\
\hline Business owner & 4 & 25.00 \\
\hline Farmer & 3 & 18.75 \\
\hline Student & 1 & 6.25 \\
\hline Vendor & 4 & 25.00 \\
\hline Unemployed & 2 & 12.50 \\
\hline \multicolumn{3}{|l|}{ Average monthly incomes varied (bath) } \\
\hline $0-5000$ & 5 & 31.25 \\
\hline $5001-10,000$ & 7 & 43.75 \\
\hline$\geq 10,000$ & 4 & 25.00 \\
\hline \multicolumn{3}{|l|}{ Health status } \\
\hline No underlying & 15 & 93.75 \\
\hline Hypertension & 1 & 6.25 \\
\hline \multicolumn{3}{|l|}{ Duration of giving care for stroke patients } \\
\hline $0-6$ months & 3 & 18.75 \\
\hline 6 months- 1 year & 8 & 50.00 \\
\hline$\geq 1$ year & 5 & 31.25 \\
\hline
\end{tabular}

Laos, and two Vietnamese; as for religion, there were 13 Buddhist and three Christian; as marital status, 11 were married and five single; eight completed the compulsory education, two high school, two the vocational/high vocational certificate, two bachelor's degree, two studying undergraduate degree, and one illiterate, respectively. Regarding career, two were employment, four business owner, two farmers, one student, four vendors, and two unemployed, respectively. Their average monthly incomes varied from 2000 to 15,000 Baht. For health status, 15 had no underlying diseases and one hypertension. The average duration of giving care for stroke patients was 0-3 years. As relation with the patient, there were five as wife, three as husband, six as children, and two as grandchildren.

Lived experiences of the stroke family caregivers residing in the border provinces of upper northeast of Thailand were reflected under van Manen four worlds.

\section{Lived body}

The caregivers reflected perception of own body, physical conditions, feelings, and emotions emerging over the course of care provision for a stroke patient. There were three themes: 


\section{Lack of knowledge}

This indicated that the caregivers lacked information or knowledge essential for providing care. This lack affected outcomes of treatments and cares, including onset of symptoms, warning sings, as well as the knowledge during care provision so as to prevent complications, which may result in complicated care or treatments.

"At first I don't think it were not so serious. He told me that he felt numbness on his arm. But, I was not suspicious and I thought it would get better. In fact, he had kept muttering about the symptom, but I ignored. I have never thought it would be like this. Only If I had paid more attention on him would he not have suffered from the disease. Lack of such knowledge of the warning sign results in the current conditions; I mean it were not as serious as now" (Informant 1).

"I am concerned about how to provide care. I am extremely nervous. I don't know what to do for the sake of the patient. For example, as for bedsores, now her bottom turns red, but there has not yet been a wound. She is pretty heavy, so it is difficult to do bodily moments. I am afraid that she is vulnerable to other health problems. He has experienced a number of diseases, including pulmonary enema, so she is prohibited from drinking a great amount of water. Such things are problematic. Previously, I hardly took care of my mother, but I just earn a living to financially support our family. My mother just handled household chores. Especially I barely take care of my mother's health conditions" (Informant 5).

\section{Fatigue}

This reflected that the caregivers experienced exhaustion caused by bearing considerable simultaneous burdens including providing cares, earning livelihood, and having underling diseases. In addition, there is change in family functioning from a family member to a family header.

"I am very exhausted. I do want her to recover. I extremely pity her. In fact, we are village health volunteers, who used to help others out. However, now it is happening in our family. Even though I have some knowledge of care provision, I sometimes feel discouraged. Different roles result in different feelings. At first, I was afraid that he might have died. I become hopelessly confused because I have no earning, having high pressure, and suffering from severe headache unless I take full rest. Now I fall in a situation in which two patients are taking care of each other" (Informant 9).

"We would be lucky if no family members suffered from illnesses. That there is a saying health is wealth is true. When facing with the illness, we run into all aspects of troubles including house chores, child raising, especially financial trouble. I live from hand to mouth; I can't cope with the situation - that's the trouble. Sometimes, I become desperate as I don't know how to deal with expenses. I am involved with medical and travel expenses. We have no transportation; I am charged with a high car rent. In addition, I have to support my kids for school, but now I am forced to stop earning for living" (Informant 11)

\section{Obligation}

It reflected that providing care for stroke patients was a duty. Attributed to family members, benefactor or couple, this responsibility is considered more important, which is a positive motivation of caregivers. "We have no children. I live with my wife. In fact, I was married with a woman, having one child, who is now married and lives with his family. After divorce, I remarried to my current wife and have spent my life with her more than 10 years almost 20 years. When she has a health problem, I am obliged to take care of her" (Informant 4).

"I'm a child, having only one mother. On no account, I have to take care of her. Unless I do, who else" (Informant 5).

\section{Lived time}

The informants reflected meanings concerning time spent during providing care for patients with stroke, which comprise three themes:

\section{Obligation Repaying}

This theme reflected the meaning that the caregivers felt obliged to express gratitude to those providing them with kindness, including parents and grandparents who brought them up.

"Previously my grandmother didn't have any underlying diseases and she could depend on herself. However, now her right part becomes slightly weak, but she remains some bodily functioning. I help her by feeding her, taking care of daily life activities. Taking care of my grandma doesn't carry me such burdens and it is time to show my gratitude to her. When I was young, my grandma raised me as my mother migrated to work. I am a bit exhausted, but it is not that much" (Informant 3).

"It is obliged for children to take care of parents. My mother becomes old, so I am bound to conventionally take care of her. It is a good thing to be admitted at the hospital because at least there are some nurses helping out rather than do ourselves. It is said that despite a number of children, mothers can manage to raise them. So, I feel good that now I can take care of my mom now. It is better to take care of her while she is still alive" (Informant 6). 


\section{Uncertainty}

This reflected the meaning that the caregivers bear a burden of care provision under the uncertain course of time. It is uncertain when care providing will end and what life from now is like. The caregivers are to provide the patients care to the death.

"Fortunately, my grandmother can live as long as now. I thought she would have passed away in 1985. I am ok with this situation because now I have a life companion. We will take care of each other to the death. We know our birthday but not death day. Reminding the trouble time, we spent together, I intend to live with her to the last day of life even though I don't know who may go first" (Informant 4).

"I am sometimes stressful and worried about everything. But, we have to take care of each other to the death. There is a possibility that either may go first. Life is uncertainty as no one knows own death day" (Informant 11)

\section{Time of retribution}

This reflected the meaning that providing care for the patients was the course of time for retribution committing in previous life and pay for karma in the present life.

"This is an inevitable fate that if I were not in this situation, no one could do it. I have to bear everything. It is my feeling that it's time of retribution. It is the worst time of my life, yet I will try my best to pay for my previous bad deed. In the previous life, we might have done something bad to each other and it is its consequences" (Informant 12).

"It is an individual karma. When paying for all karma, I probably have a better life. I may have a lot of karma. It is a Buddhist belief that what goes around, come around" (Informant 15).

\section{Lived space}

It is caregivers' perception of the place where they live. Some caregivers experienced loneliness despite living in a big and crowded place; however, in certain circumstances, despite long distance, the caregivers felt emotional warmth thanks to the modern society. Three themes emerge:

\section{Just distance}

It reflected meaning that despite long distance, the caregivers felt warm-hearted since in the advanced society, they could contact through the social media including Line, Facebook, or other information technology platforms. In addition, they exploited such technologies for medical counseling, earning livelihood, thus making them likely to have adequate time for care provision.
"She has a daughter, who is a nurse. She is my aunt. She lives in another province with her family. She rarely comes to visit her. However, whenever I have problems of her mother's health, I do video call so that she instructs me how to handle the problems. The patient always says that currently modern society is much better. She adds that previously people wrote letter to each other, which took considerable time" (Informant 3).

"I used to work in Bangkok at a garment factory. However, due to my mother's health problem, I quit my job to take care of her. I earn my living by selling cloths online. I order cloths from my friends working for that factory. They supply me goods with a reasonable price. It is fortunate to be in modern world as I can earn my living from online business; meanwhile, I can take care of my mother, or I couldn't manage to take care of my mom" (Informant 14).

\section{Being alone in the big world}

This reflected the meaning that the caregivers felt burdened as they solely take care of the patients and had feeling of helplessness and isolation.

"He has been blind almost 7-8 years because he had a motorcycle accident and something hit his eyes. It means he suffers from both blindness and stroke. It is like heaven persecuting us. I am running out of ways. I feel as if I were blind as him. I have none to ask for help. I have three children, but all of them live their own life. I am struggling to live alone, not knowing what future will be like" (Informant 8).

"When knowing that my father became sick, I felt as if the world was frozen. I felt hopeless, not knowing who I could depend on. I felt that I had to fight the problem alone and shouldered lots of burden, not knowing how I could get it over" (Informant 16).

\section{Being in a long distance}

It reflected meaning that the caregivers lived in a remote area and had difficulty to accessing the health service available, which results in outcomes of treatment, and it was not convenient for the caregivers to receive health services due to distance restrictions.

"My aunt had a warning sign. Her left limb turned numb; she could not raise her hand; her mouth became droopy; and she had difficulty speaking. A doctor told me that we were late for medication. It is a pity that we live in a distant village. If we were close to the hospital, my aunt would not have had this outcome" (Informant 1).

"I bought medicines at a clinic near my house. Sometimes, I have medicines bought by showing medicine packages. I don't know how to ride. Our children suggested to go to a nearby clinic so as not to wait for a long time. If we went to downtown, it takes a 
long time. Sometimes, we miss the bus. It is expensive to rent a car" (Informant 8).

\section{Lived relation}

This indicated relationship between caregivers and patients with stroke, comprising three themes.

\section{Blood is thicker than water}

This reflected the meaning that the caregivers were offered help from relatives and kin to bear responsibilities to provide care for the patients, thereby making it likely to mitigate problems. The patients felt warm and reliable once the caregivers had relatives to help or run errands.

"My grandmother can manage eating on her own and simply sit and stand, but she has difficulties walking. Most of the time she either lies on the bed or sits still. I prepare necessary stuff near her bed. If I sometimes come home late, I ask my relatives or cousins to come over. I don't leave the patient alone. The situation is getting better as I have some time to take a rest. Having relatives to help is reliable" (Informant 4).

"I wish I had a dozen of siblings. When one faces with illness, we can depend or take care of one another. Like a saying, blood is thicker than water. That is, we can appreciate each other when in trouble. It is better to bother others" (Informant 15).

\section{Community network}

It reflected that the caregivers received help and encouragement from their community members although they are not blood relatives.

"The neighbors residing in the neighborhoods usually come over, bring some food, and have a talk, which encourages one another as a senior group" (Informant 4).

"It is better now as we have the social media such as Facebook or Line. We use these platforms to ask for advice regardless of distance. In addition, these media help us to relive our loneliness and boredom when we chat. In the rural community, we comfortably visit one another and share stuff. This is a different experience. When I worked in Bangkok, after work, we lived in own room and had our own private life. I went to the church on Sunday, wishing the God to bless us recovery from the illness. Generally speaking, living in the rural village is cozier than do in Bangkok" (Informant 14).

\section{Needs from the health service units}

The caregivers reflected meaning intended to health personnel to assure the quality of both physical and mental health.
"I have to rely on the doctors. I feel confident that whenever l' $m$ not fine, I am with the doctors. However, I wish there were home delivery of medication because I'm charged a lot of money for various fees. It must be a good idea if such services were available, like a mobile doctor. This system probably greatly facilitates the old persons" (Informant 8).

"I wish there was a follow-up system including telephone numbers or a team for $24 \mathrm{~h}$ direct contact. Especially, it would be a good idea if those personnel have our information for continued care, like a personal doctor or nurse" (Informant 10).

\section{Discussion}

In this study, we explored experiences of stroke family caregivers in the context of in the border provinces of the upper northeast of Thailand. The results showed the 12 important themes. The first theme was lack of knowledge; in that, the caregivers had limited knowledge or information essentially used to provide care for the patients, which results in poor outcomes of treatment or care. Particularly, the caregivers appeared unaware of the warning sign of stroke and the knowledge of prevention against stroke and complications. Again, this knowledge influenced long-term outcome of treatments. This finding corroborates that of Nuanate and Srikha [14] who found that as high as $46.5 \%$ of the patients did not realize the warning sign of stroke. In addition, according to Thongthawee et al. [15], the family caregivers of stroke patients in their family were reported to have inadequate knowledge of providing care for stroke patients, leading to unsatisfactory outcomes of treatment. Interesting, the findings also suggested that despite the availability of the media on stroke care and prevention and the sophisticated medical technologies, low socioeconomic status and the livelihood of the caregivers (e.g., employment, smallscale merchants, and agriculture) may result in poor health outcomes. According to WHO guidelines, health promotion is to make individuals willing to implement self-care so that they can eventually improve all aspects of health including physical, mental and social health status; however, to achieve health behaviors, individuals are required to have such continued commitment that self-care behaviors become their lifestyle and health habits [16], [17]. The second theme was fatigue; in that, the caregivers experienced discouragement since they were engaged in a variety of burdens at one time, including providing care for the patients and taking other roles. It was a serious case for a member objected to change to be a family header who bore family's financial burdens and expenses, which caused the caregivers impaired health. These results support a previous study of Ckumdee et al. [18], [19] that once experiencing caregiving for a stroke patient, the caregivers were 
provoked to adapt themselves to exist after 6-month exposure. However, they found that some caregivers had difficulty adapting themselves to the situation despite 6 months passing. Interestingly, positive motivation was found among some caregivers. Some caregivers felt a responsibility to provide the patients care although they remained responsibility of their own family. The caregivers had a full obligation to express gratitude to the patients. This reflects legitimate culture of expressing sense of obligation. This finding is consistent with that of Chansangrat et al. [20]. On the other hand, certain negative motivations were also reported. To illustrate, the caregivers experienced fatigue due to burden bearing and struggling on their own, uncertainty in future life, and anxiety of unanticipated life events. In addition, they lacked confidence in future live as their children or grandchildren left caregivers to have their own family and bare own burdens, making them unlikely to take care of the patients. The study of Chansangrat et al. [20] also revealed the negative motivation from the caregivers who experienced feeling of pressure and boredom. However, Roy's and Andrews theory suggests that people adaptation accommodates constant change and parallel with interaction of inside and outside environment. The adaptation comprises three attributes: Integrated level of adaptation, compensatory level of adaptation, and compromised level of adaptation. In other words, successful adaptation of caregivers may contribute to positive health outcomes of both patients and caregivers themselves; indeed, whether to achieve adaptation varies according to personal and environment factors [21].

Another negative response reflected by the caregivers was distant residence, which deprived them of the health services and economic hardship. Despite the negative motivation, complicated technologies reduce distance. At present, the modern world provides the caregivers with a variety of channels, applications, or platforms such as telemedicine or Line. Moreover, a further implication of this study is that the advanced communication technologies such as online business can ease livelihood, thereby making it easier to take care of the patients. Furthermore, advancement in medical and nursing technologies helped the stroke family caregivers deliver effective critical care [22]. Another positive motivation was the assistance from relatives; in that, once receiving assistance from relatives, the caregivers realized warm affection, reassurance, and confidence. This finding is consistent with that of Koonnarong et al. [23] who argued that strong relationship among family members and relatives who offered active assistance contributed to stress reduction of the primary caregivers. It was the case that in the bordered or marginalized communities, social support, strong community network, community contribution, and hospitality remained functioning, which brought the caregivers considerable support. The primary caregivers were confronted with such inherent problems as prognosis of the disease, stress, economic burdens, tough decision, and complication management; thus, communities where caregivers reside play a crucial role in providing the essential supports. Similar to the finding of Hare et al. [24], providing that patients and their caregivers live in a community with effective social support, quality of life, and treatment outcomes tended to improve. Finally, the caregivers reflected their need from the health service units. The service systems required by the caregivers included continued treatment and consultation services helpful in assessing appropriate relevant decision and care together with adequate medical equipment with quality and affordable prices. Furthermore, the caregivers also suggested to establish a professional unit responsible for promoting additional family income, reducing stress and economic burden, strengthening positive motivation of caregivers and community, as well as exploiting latest technology for improved health outcomes of caregivers and patients.

\section{Conclusion}

The findings from the current study extend our understanding of caregivers of stroke patients in the context of a border province. The results from this study can be used to prepare and promote health outcomes of caregivers of stroke patients.

\section{Recommendation and Implication}

It is recommended to further develop a specific program designed to provide caregivers with preparedness for delivering stroke patient care. In addition, such program should consider assisting caregivers in respect of social support, stress-relieving activities, and activities to improve relationship between caregivers and patients. The findings can be used to encourage and motivate the relevant personnel or authorities to adopt continued care services, launch proactive health-care system, implement promotion and prevention, education, undergo stroke screening of vulnerable group, develop competency of caregivers, and develop a community model of care provision for stroke patients.

\section{Acknowledgments}

The authors would also like to thank the caregiver and patients, Nakhon Phanom, Thailand, for cooperation in data collection. 


\section{References}

1. American HeartAssociation. Heart Disease and Stroke Statistics Update Fact Sheet At-a-Glance; 2021. Available from: https:// www.heart.org/-/media/phd-fif iles-2/science-news/2/2021heart-and-strokeupdate/2021_heart_disease_and_stroke_ statistics_update_fact_sheetat_a_glance.pdf. [Last accessed on 2021 Feb 26]. https://doi.org/10.1161/cir.0000000000000530

2. Manosunthorn S. Factor influencing pre-hospital delay among acute ischemic stroke patients in Rajavithi hospital. Thai Stroke Soc. 2014;7(1):22-9.

3. Chanchai A, Chooyingsakultip N, Katudom P, Kaewdaeng K, et al. Effect of stroke care program on knowledge and skills in patient care level of ability to perform daily activities rate of incidence, complications, and level of caregiver/patient satisfaction with program care. Acute cerebrovascular disease hospitalized in Rayong. J Phrapokklao Nurs Coll Chanthaburi. 2014;25(1):78-89.

4. Godwin KM, Ostwald SK, Cron SG, Wasserman J. Long-term health-relate quality of life of stroke survivors and their spousal caregivers. J Neurosci Nurrs. 2013;45(3):145-54.

PMid:23558977

5. Vasusathien P. Health promotion behevior of people who were at risk on stroke disease in health region 6. Depart Health Support J. 2018;14(1):42-53.

6. Jeong YG, Jeong YJ, Kim WC, Kim JS. The mediating effect of caregiver burden on the caregiver' quality of life. J Phys Ther Sci. 2015;27(5):1543-7. https://doi.org/10.1589/jpts.27.1543 PMid:26157260

7. Ganapathy V, Graham GD, DiBonaventura MD, Gillard PJ, Goren A, Zorowitz RD, et al. Caregiver burden, productivity loss, and indirect costs associated with caring for patients with poststroke spasticity. Clin Interv Aging. 2015;10:1793-802. https://doi.org/10.2147/cia.s91123

PMid:26609225

8. Olai L, Burgquist L, Svardsudd K. Life situations and the care burden for stroke patients and their informal caregivers in a prospective cohort study. Ups J Med Sci. 2015;120(4):290-8. https://doi.org/10.3109/03009734.2015.1049388 PMid:26074171

9. Ekuchechakun S, Kongtan A, Saranritthichai G. Development of the community participatory palliative care for stroke survivors in primary care network, Khon Kean hospital. J Nurs Health. 2014;37(3):84-93.
10. Tong A, Sainsbury P, Craig J. Consolidated criteria for reporting qualitative research (COREQ): A 32-item checklist for interviews and focus groups. Int J Qual Health Care. 2007;19(6):349-57. https://doi.org/10.1093/intqhc/mzm042

11. Heidegger M. In: MacQuaeeie J, Robinson E, editors. Being and Time. New York: Harper and Row; 1962.

12. Van Manen M. Researching Lived Experience: Human Science for an Action Sensitive Pedagogy. New York: SUNY Press; 1990.

13. Lincoln YS, Guba EG. Paradigmatic controversies, contradictions, and emerging confluences. In: Denzin NK, Lincoln YS, editors. The Sage Handbook of Qualitative Research. $3^{\text {rd }}$ ed. Thousand Oaks: SAGE; 2005. p. 191-215.

14. Nualnetr N, Srikha D. Knowledge on the stroke and behaviors to reduce the risk of stroke among risk persons in Samliam community, Muang district, Khon Kaen Province. J Med Tech Phy Ther. 2012;24(3):318-26.

15. Thongthawee B, Matchim Y, Kaewsriwong S. Family members' experience in providing care for persons with stroke: A phenomenological study. Songklanagarind J Nurs. 2018;38(3):179-91.

16. World Health Organization. Health Promotion Glossary. Geneva: World Health Organization; 1998.

17. Pender NJ. Health Promotion in Nursing Practice. $3^{\text {rd }}$ ed. Stamford, CT: Appleton and Lange; 1996.

18. Ckumdee S, Arpanantikul M, Sirapo-ngam Y. Family caregivers adjustment problems in caring for stroke patients. Thai J Nurs Counc. 2014;29(4):45-63.

19. Sirapo-Ngam Y. Family care giver: Concept and research issue. Rama Nur J. 2015;2(1):84-93.

20. Chansangrat N, Phibal A, Samael L, Thiratchakul J. Experiences in dementia care among nursing students at the Faculty of Nursing Princess of Naradhiwas University. Thai $\mathrm{J}$ Nurs. 2014;63(4):29-34.

21. Roy SC, Andrews HA. The Roy Adaptation Model. $2^{\text {nd }}$ ed. Connecticut: Appleton and Lange; 1999.

22. Rerkkasem K. Pathophysiology and Management in Carotid Artery Stenosis. Bangkok: Beyond Enterprise; 2009.

23. Koonnarong $\mathrm{O}$, Thaniwatananont $\mathrm{P}$, Kitrungrote $\mathrm{L}$. Caregiving preparedness, family relationships and role strain among caregivers of Muslim stroke patients. Princess Naradhiwas Univ J. 2012;4(1):14-27.

24. Hare R, Rogers H, Lester H, McManus RJ, Mant J. What do stroke patients and their carers want from community services? Fam Pract. 2006;23(1):131-6. https://doi.org/10.1093/fampra/ cmi098

PMid: 16308328 